\title{
Surgical treatment of rectal cancer with a Retzius shunt: a case report
}

\author{
Toshinori Sueda $^{1 *}$ D, Mitsuyoshi Tei ${ }^{1}$, Haruna Furukawa', Tae Matsumura', Chikato Koga', Masaki Wakasugi', \\ Hiromichi Miyagaki', Ryohei Kawabata', Junzo Shimizu', Atsuya Okada² and Junichi Hasegawa'
}

\begin{abstract}
Background: A case of a short circuit (Retzius shunt) from the inferior mesenteric vein (IMV) to the inferior vena cava (IVC) without accompanying portal hypertension due to liver cirrhosis is rare.

Case presentation: An 83-year-old woman who was followed after surgery for thyroid and breast cancer was incidentally found to have rectal cancer on computed tomography (CT). Preoperative three-dimensional CT showed a venous malformation forming a short circuit (Retzius shunt) from the IMV to the IVC. Laparoscopic anterior rectal resection was performed. Operative findings included the Retzius vein crossing the abdominal aorta and the inferior mesenteric artery (IMA) to the IVC and a number of engorged vessels in the mesentery. The Retzius vein and IMA were clipped without major bleeding, and tumor-specific mesorectal excision was then performed. The patient's postoperative clinical course was good, and she was discharged without complications.

Conclusions: Preoperative imaging enabled identification of an unexpected rare disease, thus reinforcing the importance of preoperative imaging.
\end{abstract}

Keywords: Venous malformation, Retzius shunt, Rectal cancer

\section{Background}

The veins of Retzius are rare and may be primary (congenital or idiopathic) or secondary due to portal hypertension or trauma, or iatrogenic. A case of a short circuit (Retzius venous short circuit) from the inferior mesenteric vein (IMV) to the inferior vena cava (IVC) without accompanying portal hypertension due to liver cirrhosis is extremely rare [1-3]. The veins of Retzius are important, because they can be injured during surgery, and they may provide a pathway for the hematogenous spread of colorectal cancer.

A case in which an unexpected Retzius venous short circuit between the IMV and IVC was discovered during three-dimensional computed tomography (3D-CT) prior to surgery is presented. Using this information, laparoscopic anterior resection was safely performed. Preoperative $3 \mathrm{D}-\mathrm{CT}$ is useful for understanding the anatomy to ensure a safe, precise operation. The present case study highlights the importance of preoperative imaging.

\footnotetext{
* Correspondence: sueda811@yahoo.co.jp

'Department of Surgery, Osaka Rosai Hospital, 1179-3 Nagasonecho, Kita-ku, Sakai 591-8025, Japan

Full list of author information is available at the end of the article
}

\section{Case presentation}

The case of an 83-year old woman with a history of thyroid cancer, breast cancer, and rheumatoid arthritis is presented. She had no relevant family history. After surgery for thyroid and breast cancers, elevations of carcinoembryonic antigen and carbohydrate antigen 19-9 were observed. She had no abdominal tenderness, and no mass was palpable. Laboratory results were unremarkable. Colonoscopy showed a type 2 tumor localized in the upper rectum (Fig. 1a). Following biopsy, the lesion was confirmed to be moderately differentiated adenocarcinoma. Contrast CT examination showed wall thickening of rectal cancer and swollen lymph nodes, but there were no distant metastases (Fig. 1b). In addition, abdominal contrast CT examination also revealed vascular anomaly (Fig. 2a-d). Laparoscopic surgery was planned, and a $3 \mathrm{D}-\mathrm{CT}$ was constructed from contrast $\mathrm{CT}$ images to investigate local vascularity. The 3D-CT scan showed a venous malformation forming a short circuit (Retzius shunt) from the IMV to the IVC (Fig. 3a, b).

Based on these findings, upper rectal cancer with a Retzius shunt from the IMV to the IVC was diagnosed. 

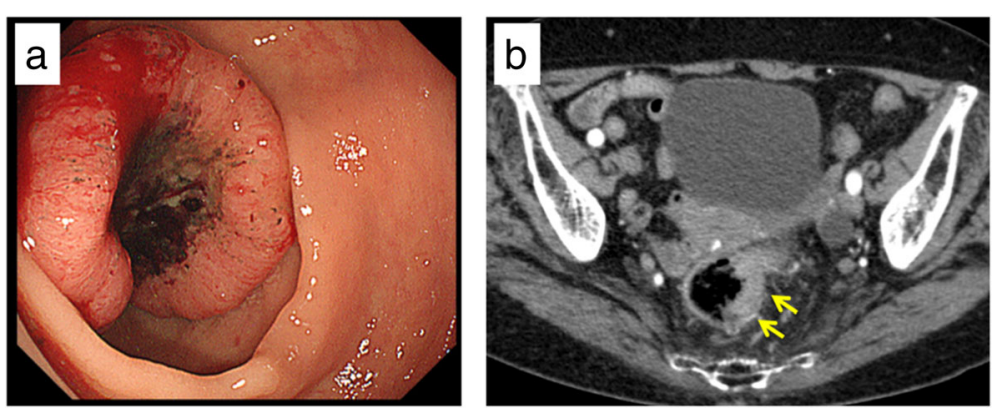

Fig. 1 Preoperative findings. a Preoperative colonoscopy shows a type 2 tumor localized in the upper rectum. b An abdominal contrast CT scan shows wall thickening of the rectum (yellow arrows)

Laparoscopic anterior resection was performed. Laparoscopic observation showed a number of engorged vessels in the mesentery (Fig. 4a) and the Retzius vein crossing the abdominal aorta and inferior mesenteric artery (IMA) to the IVC (Fig. 4b, c). The Retzius vein and IMA were clipped without major bleeding (Fig. 4d), and then tumor-specific mesorectal excision was completed. The patient was discharged on the 14th day after surgery with no complications. Histological examination showed the tumor to be moderately differentiated adenocarcinoma with invasion of the subserosa (T3) and lymph node metastasis (N2). No distant metastases were found (M0) at the time of surgery. The histological TNM staging of the tumor was stage IIIB, with no other remarkable findings.

\section{Discussion}

The present case highlights the usefulness of preoperative examination. Careful preoperative examination showed a rare venous malformation, which reduced the stress of the surgeons and improved operative accuracy.

Retzius reported cases of a short circuit from the duodenum to the IVC and from the left colon to the left renal vein in 1835 [1]. The retroperitoneal intestinal vein-general circulation anastomotic pathway is now called the Retzius vein [2, 3]. The cause of a Retzius venous shunt is not completely understood; however, two major theories have been proposed [3-7]. The first is the congenital origin theory, which suggests persistence of the communication between the portal and caval systems that occurs during embryonal development. The
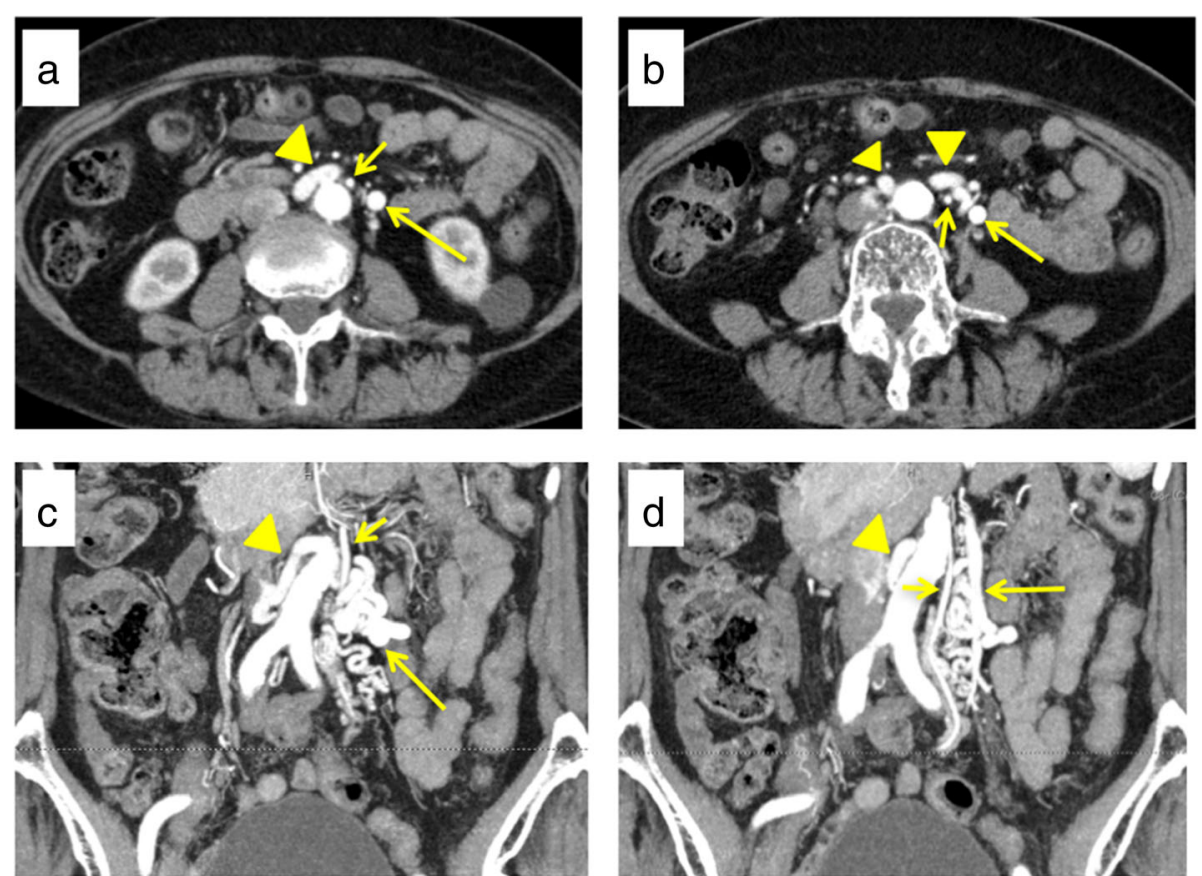

Fig. 2 An abdominal contrast CT scan shows a venous malformation forming a short circuit (Retzius shunt) from the IMV to the IVC. a, b Axial views. c, d Coronal views. Retzius shunt (arrow head). IMV (long arrow). IMA (short arrow) 


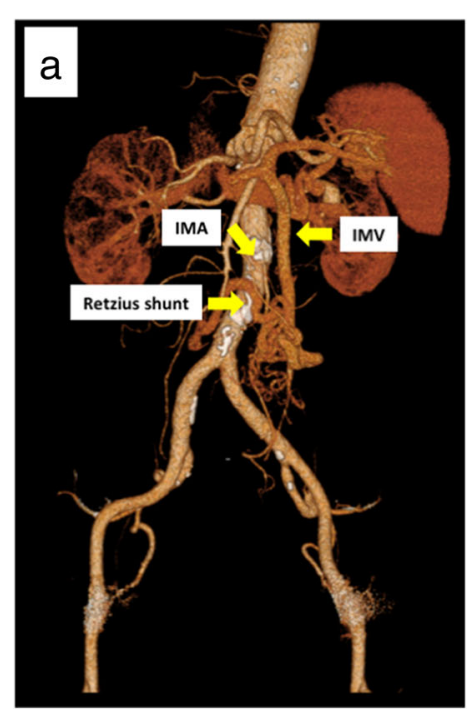

b

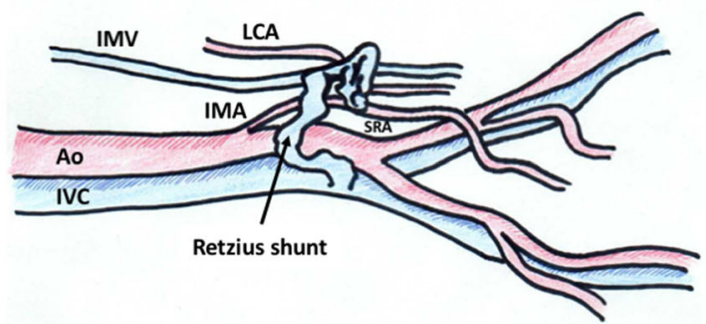

Fig. 3 Preoperative 3D-CT scan of vessels shows dilated veins in the inferior mesenteric area and the Retzius vein crossing the abdominal aorta and IMA to the IVC. a Frontal view. b Lateral view (hand-drawn picture). IMA inferior mesenteric artery, IMV inferior mesenteric vein, IVC inferior vena cava, LCA left colic artery, SRA superior rectal artery, Ao abdominal aorta

second is the acquired theory, which suggests that the shunt results from trauma, portal hypertension by liver cirrhosis, etc. A Retzius venous shunt usually occurs in patients with portal hypertension and is mainly induced by liver cirrhosis, but it can sometimes occur in patients who do not have liver cirrhosis. In fact, a previous imaging study showed that the veins of Retzius were demonstrated on CT arterial portography in approximately 50\% of patients with and $50 \%$ of patients without liver cirrhosis [8]. The presently described patient had no liver cirrhosis or history of trauma. Thus, the Retzius venous shunt in the present case was thought to be congenital in origin.

Preoperative risk assessment is an important aspect of surgical planning because it helps surgeons identify

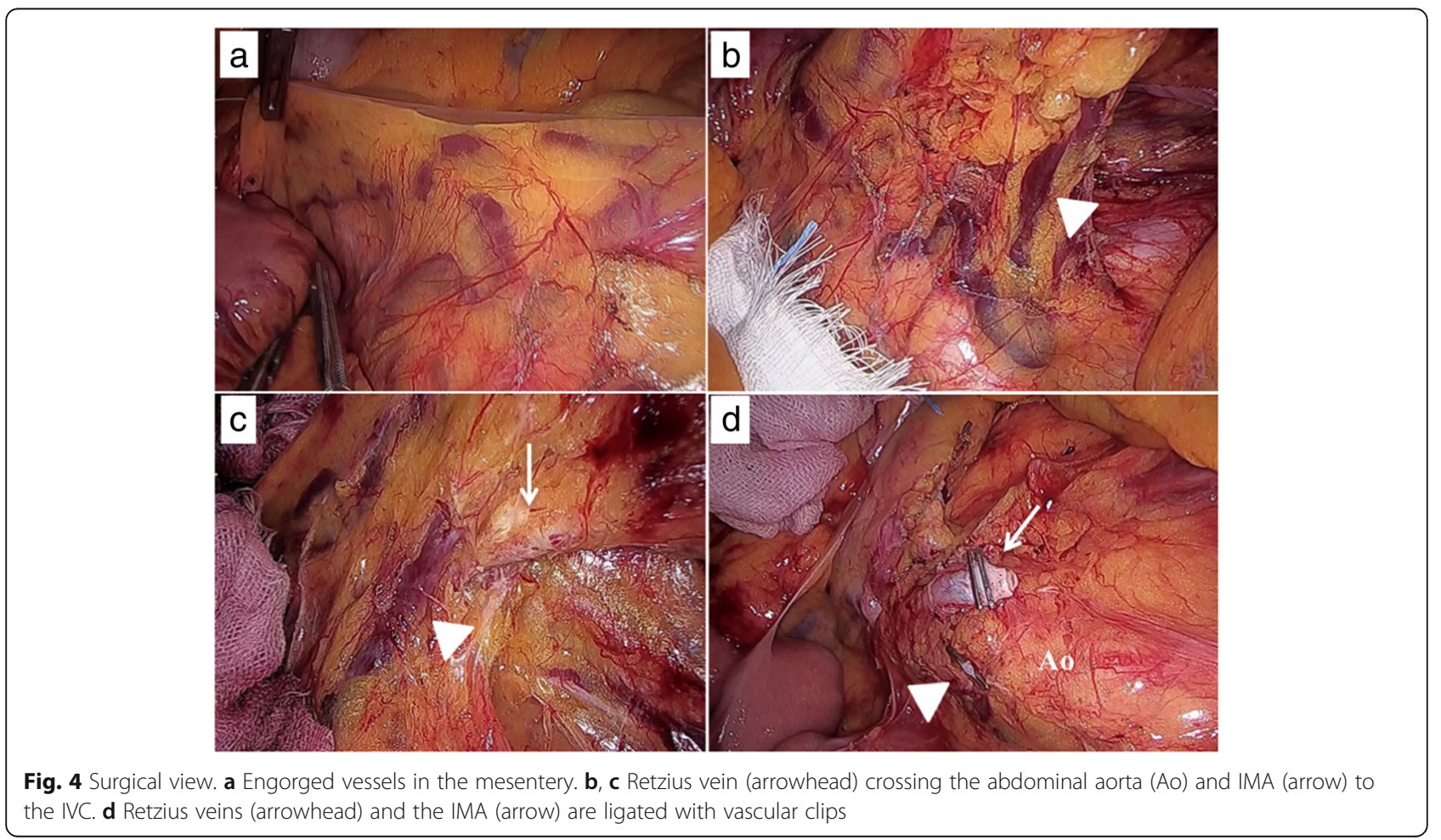


patients with an increased risk of a poor postoperative outcome [9]. CT imaging is widely available, and all patients with cancer routinely undergo preoperative $\mathrm{CT}$ for staging. Recently, 3D-CT was shown to help in the preoperative assessment of vascular anatomy for laparoscopic lymph node dissection. The 3D-CT is a combined technology of a conventional CT scan with that of traditional angiography to create detailed images of vessels in the body, and noninvasive and provides highly reliable and reproducible vascular anatomy. Furthermore, 3D-CT also allows noninvasive vascular assessment and is used widely in preoperative planning workups for patients requiring laparoscopic surgery and in the evaluation of vascular anomaly and other vascular conditions [10]. When the preoperative 3D-CT is obtained for these purposes, it can simultaneously serve as a tool for preventing a serious situation, such as an unexpected bleeding or conversion to open surgery, during laparoscopic surgery. In fact, several authors reported that imaging of vascular anatomy with 3D-CT facilitates surgery [11-19]. We also use $3 \mathrm{D}-\mathrm{CT}$ constructed from routine contrast CT images to preoperatively evaluate the tumor-feeding artery, drainage vein, and vascular anatomy. In the present case, 3D-CT unexpectedly showed a Retzius venous short circuit between the IMV and IVC. Laparoscopic surgery with a Retzius venous short circuit would have been dangerous without the detailed preoperative examination, but the preoperative information acquired by $3 \mathrm{D}-\mathrm{CT}$ made the surgery the safest operation possible. Based on this case report, we would like to stress the importance of recognizing the veins of Retzius which, if unrecognized, could lead to significant vascular complications, including hemorrhage. As the resolution of $\mathrm{CT}$ increases, the importance of preoperative imaging for patients with vascular malformations will be even greater in the future.

\section{Conclusions}

In the present case, preoperative imaging enabled the discovery of an unexpected rare venous malformation. The information obtained from this preoperative examination was sufficient to enable adequate safety precautions and to perform curative resection with laparoscopic surgery, without any complications. The present case re-affirms the importance of preoperative diagnosis for patients with vascular abnormalities.

\footnotetext{
Abbreviations

3D-CT: Three-dimensional computed tomography; Ao: Abdominal aorta; CT: Computed tomography; IMA: Inferior mesenteric artery; IMV: Inferior mesenteric vein; IVC: Inferior vena cava; LCA: Left colic artery; SRA: Superior rectal artery
}

Acknowledgements

Not applicable.
Funding

Not applicable.

Availability of data and materials

Please contact author for data requests.

\section{Authors' contributions}

All authors managed the perioperative course. TS and MT performed the operation. TS and MT contributed to the drafting and the manuscript. All authors read and approved the final manuscript.

Ethics approval and consent to participate

Not applicable.

\section{Consent for publication}

Written, informed consent was obtained from the patient for publication of this case report and any accompanying images. A copy of the written consent is available for review by the Editor-in-Chief of this journal.

\section{Competing interests}

The authors declare that they have no competing interests.

\section{Publisher's Note}

Springer Nature remains neutral with regard to jurisdictional claims in published maps and institutional affiliations.

\section{Author details}

'Department of Surgery, Osaka Rosai Hospital, 1179-3 Nagasonecho, Kita-ku, Sakai 591-8025, Japan. ${ }^{2}$ Department of Diagnostic and Interventional Radiology, Osaka Rosai Hospital, 1179-3 Nagasonecho, Kita-ku, Sakai 591-8025, Japan.

Received: 28 December 2018 Accepted: 6 February 2019 Published online: 18 February 2019

\section{References}

1. Retzius AA. Bemerkungen unter anastomosen zwischen der pfortader und untern hohlader ausserhalb der leber. Ztschr Physiol. 1835;5:105-6.

2. Hollinshead WH. Portal hypertension. in Anatomy for surgeons, Vol 2, 2nd ed, by W. Henry Hollinshead, Harper \& Row, New York. 1971, 450-453.

3. Mclndore AH. Vascular lesions of portal cirrhosis. Arch Pathol. 1928;5:23-42.

4. Akahoshi T, Nishizaki T, Wakasugi K, Mastuzaka T, Kume K, Yamamoto I, et al. Portal-systemic encephalopathy due to a congenital extrahepatic portosystemic shunt: three cases and literature review. HepatoGastroenterology. 2000;47:1113-6.

5. Kerlan RK Jr, Sollenberger RD, Palubinskas AJ, Raskin NH, Callen PW, Ehrenfeld WK. Portal-systemic encephalopathy due to a congenital portocaval shunt. AJR Am J Roentgenol. 1982;139:1013-5.

6. Ikeda S, Sera Y, Ohshiro H, Uchino S, Uchino T, Endo F. Surgical indication for patients with hyperammonemia. J Pediatr Surg. 1999:34:1012-5.

7. Henderson JM. Treatment of post-shunt portal systemic encephalopathy by embolization of the shunt. Hepatology. 1989;9:164-5.

8. Ibukuro K, Tsukiyama T, Mori K, Inoue Y. Veins of Retzius at CT during arterial portography: anatomy and clinical importance. Radiology. 1998; 209:793-800.

9. Sueda T, Takahashi H, Nishiura J, Hata T, Matsuda C, Mizushima T, et al. Impact of low muscularity and myosteatosis on long-term outcome after curative colorectal cancer surgery: a propensity score-matched analysis. Dis Colon Rectum. 2018;61:364-74

10. Murono K, Kawai K, Ishihara S, Otani K, Yasuda K, Nishikawa T, et al. Evaluation of the vascular anatomy of the right-sided colon using threedimensional computed tomography angiography: a single-center study of 536 patients and a review of the literature. Int J Color Dis. 2016;31:1633-8.

11. Kobayashi M, Morishita S, Okabayashi T, Miyatake K, Okamoto K, Namikawa $\mathrm{T}$, et al. Preoperative assessment of vascular anatomy of inferior mesenteric artery by volume-rendered 3D-CT for laparoscopic lymph node dissection with left colic artery preservation in lower sigmoid and rectal cancer. World J Gastroenterol. 2006;12:553-5.

12. Takiguchi S, Fujiwara Y, Yamasaki M, Miyata H, Nakajima K, Nishida T, et al. Laparoscopic intraoperative navigation surgery for gastric cancer using realtime rendered 3D CT images. Surg Today. 2015;45:618-24. 
13. Hirai K, Yoshinari D, Ogawa H, Nakazawa S, Takase Y, Tanaka K, et al. Threedimensional computed tomography for analyzing the vascular anatomy in laparoscopic surgery for right-sided colon cancer. Surg Laparosc Endosc Percutan Tech. 2013;23:536-9.

14. Matsuki M, Okuda J, Kanazawa S, Kanamoto T, Inada Y, Tatsugami F, et al. Virtual CT colectomy by three-dimensional imaging using multidetector-row CT for laparoscopic colorectal surgery. Abdom Imaging. 2005;30:698-708.

15. Ogino T, Takemasa I, Horitsugi G, Furuyashiki M, Ohta K, Uemura M, et al. Preoperative evaluation of venous anatomy in laparoscopic complete mesocolic excision for right colon cancer. Ann Surg Oncol. 2014;21(Suppl 3):S429-35.

16. Tamai K, Takemasa I, Uemura M, Nishimura J, Hata T, Higashihara H, et al. Single-site laparoscopic colectomy for rectosigmoid cancer with middle aortic syndrome: report of a case. Surg Case Rep. 2015;1:53. https://doi.org/ 10.1186/s40792-015-0050-4

17. Ishikawa Y, Ehara K, Yamada T, Matsuzawa N, Arai S, Ban D, et al. Threedimensional computed tomography analysis of the vascular anatomy of the splenic hilum for gastric cancer surgery. Surg Today. 2018;48:841-7.

18. Yamashita K, Sakuramoto S, Mieno H, Shibata T, Nemoto M, Katada N, et al. Preoperative dual-phase 3D CT angiography assessment of the right hepatic artery before gastrectomy. Surg Today. 2014;44:1912-9.

19. Nesgaard JM, Stimec BV, Bakka AO, Edwin B, Ignjatovic D. RCC study group. Navigating the mesentery: a comparative pre- and per-operative visualization of the vascular anatomy. Color Dis. 2015;17:810-8.

\section{Submit your manuscript to a SpringerOpen ${ }^{\circ}$ journal and benefit from:}

- Convenient online submission

- Rigorous peer review

- Open access: articles freely available online

- High visibility within the field

- Retaining the copyright to your article

Submit your next manuscript at $\boldsymbol{\nabla}$ springeropen.com 